Check for updates

Cite this: RSC Adv., 2018, 8, 6373

\title{
High voltage, solvent-free solid polymer electrolyte based on a star-comb PDLLA-PEG copolymer for lithium ion batteries $\uparrow$
}

\author{
Bingbing Wang, ab Hongming Lou, (D) a Hongli Xu, ${ }^{\mathrm{b}}$ Junpeng Zhao, (D) c Qiujun Wang, ${ }^{\mathrm{d}}$ \\ Qiao Shi ${ }^{\mathrm{d}}$ and Yonghong Deng (iD *b
}

In this work, a novel star-comb copolymer based on poly(d,L-lactide) (PDLLA) macromonomer and poly(ethylene glycol)methyl ether methacrylate (PEGMA) was prepared, and the electrochemical properties were studied, with the aim of using it as a solid polymer electrolyte in lithium ion batteries. The six-arm vinyl functionalized PDLLA macromonomer was synthesized by a ring-opening polymerization (ROP) of D,L-lactide and subsequently an acylation of the hydroxy end-groups. A series of free-standing solid polymer electrolyte membranes from different ratios of PDLLA, PEGMA and LiTFSI were prepared through solvent-free free radical polymerization under UV radiation. The chemical structure of the obtained polymers was confirmed by ${ }^{1} \mathrm{H}$ NMR and FTIR. The as-prepared six-arm starcomb solid polymer electrolytes (PDLLA-SPEs) exhibit good thermal stability with $T_{\mathrm{d}}{ }^{5 \%} \mathrm{~S}$ of $\sim 270{ }^{\circ} \mathrm{C}$ and low $T_{\mathrm{g}} \mathrm{S}$ of -48 to $-34{ }^{\circ} \mathrm{C}$. The electrochemical characterization shows that the PDLLA-SPEs possess a wide electrochemical window up to $5.1 \mathrm{~V}$ with an optimal ionic conductivity of $9.7 \times 10^{-5} \mathrm{~S} \mathrm{~cm}^{-1}$ at $60{ }^{\circ} \mathrm{C}$ at an $\mathrm{EO} / \mathrm{Li}^{+}$ratio of $16: 1$. Furthermore, the all-solid-state $\mathrm{LiFePO}_{4} / \mathrm{Li}$ cells display extraordinary cycling and rate performances at $60^{\circ} \mathrm{C}$ by curing the PDLLA-SPEs directly on the cathode. These superior properties of the six-arm star-comb PDLLA-SPE make it a promising candidate solid electrolyte for lithium batteries.

Received 26th December 2017 Accepted 1st February 2018

DOI: $10.1039 / c 7 r a 13664 a$

rsc.li/rsc-advances electrolytes only reaches an order of magnitude of $10^{-7} \mathrm{~S} \mathrm{~cm}^{-1}$ at ambient temperature. ${ }^{4}$ Besides, the electrochemical stability window of PEO is lower than $4 \mathrm{~V}$, restricting the selection of cathode materials. ${ }^{5}$ Various strategies have been carried out to improve electrochemical properties of PEO, such as blending, ${ }^{6}$ copolymerization, ${ }^{7}$ and crosslinking. ${ }^{8}$ Among these approaches, preparing copolymers, especially graft copolymers, can decrease the crystallinity of a PEO-based solid electrolyte system effectively. As a result, the ionic conductivities are improved and also the mechanical properties of SPEs are enhanced in some cases. Ding et al. reported the synthesis of amorphous comb-like SPEs from methyl vinyl ether/maleic anhydride copolymer with oligo(oxyethylene) side chains, which shows a maximum conductivity of $4.9 \times 10^{-5} \mathrm{~S} \mathrm{~cm}^{-1}$ at $25^{\circ} \mathrm{C}^{9}{ }^{9}$ Daigle et al. reported a set of SPEs based on comb-like copolymers originated from styrene (St), 4-vinylanisole (VA) and PEGMA, which shows good conductivity $\left(6.8 \times 10^{-5} \mathrm{~S} \mathrm{~cm}^{-1}\right)$ at room temperature. ${ }^{10}$ What's more, preparing multi-arm star-shaped copolymer with both rigid core and flexible segment is another effective way to suppress crystallinity of SPE matrix, as well as to improve mechanical properties. ${ }^{11-13}$ According to the pioneering work, star-shaped copolymers based SPEs usually show improved ambient conductivities $\left(\sim 10^{-5} \mathrm{~S} \mathrm{~cm}^{-1}\right) \cdot{ }^{11-15}$ As a bonus, the mechanical performance of the SPE films can be improved significantly by introducing the rigid component. ${ }^{12}$ 
Another widely studied polymer matrix for SPE is polyester, which has wide electrochemical window and high permittivity. Brandell's group reported a flexible poly(trimethylene carbonate) (PTMC)-based SPE with LiTFSI, of which the electrochemical window is up to $5.0 \mathrm{~V}\left(v s . \mathrm{Li} / \mathrm{Li}^{+}\right)$and the ionic conductivity is in an order of $10^{-7} \mathrm{~S} \mathrm{~cm}^{-1}$ at $60{ }^{\circ} \mathrm{C}^{16}$ Chai et al. fabricated a poly(vinylene carbonate) (PVC) based SPE by in situ polymerization, the electrochemical stability window and the ionic conductivity can reach $4.5 \mathrm{~V}\left(v s . \mathrm{Li} / \mathrm{Li}^{+}\right.$) and $9.8 \times$ $10^{-5} \mathrm{~S} \mathrm{~cm}^{-1}$ at $50{ }^{\circ} \mathrm{C}$, respectively. ${ }^{17}$ Due to its high modulus and low elongation, ${ }^{\mathbf{1 8 , 1 9}}$ using polylactide as an electrolyte matrix was seldom reported. Chew et al. first prepared a polylactide-based gel polymer electrolyte (GPE) with lithium perchloride $\left(\mathrm{LiClO}_{4}\right)$ as a salt, ethylene carbonate (EC) as a plasticizer and silicon dioxide ceramic $\left(\mathrm{SiO}_{2}\right)$ as a filler by typical solution casting technique, but the ambient ionic conductivity is only $1.29 \times 10^{-5} \mathrm{~S} \mathrm{~cm}^{-1}$ without any extra electrochemical properties reported. ${ }^{20}$ Tan et al. developed a SPE from polylactide-poly(ethylene glycol) (PDLLA-PEG) block copolymer with lithium iodide as a salt, which achieved an optimum ionic conductivity of $4.17 \times 10^{-6} \mathrm{~S} \mathrm{~cm}^{-1}$ at room temperature. $^{21}$ PDLLA was selected in his work, rather than PLLA or PDLA, was due to the highly amorphous nature of PDLLA, which favors $\mathrm{Li}^{+}$ionic transportation. ${ }^{22}$

In this work, a six-arm poly(d,L-lactide) (PDLLA) macromonomer that end-capped with vinyl functionalities was prepared via a ring-opening polymerization (ROP) of D,L-lactide and an acylation of the hydroxy end-groups. A series of novel free-standing star-comb PDLLA-based solid polymer electrolytes (hereafter abbreviated as "PDLLA-SPE") with six-arm PDLLA as core, poly(ethylene glycol)methyl ether methacrylate (PEGMA) as side chains and LiTFSI as conducting salt were prepared through free radical polymerization under UV radiation. To the best of our knowledge, this is the first example of design and use a star comb-like block copolymer from a multi-arm PDLLA with branching PEG side chains as SPE for lithium ion batteries. The multi-arm PDLLA is anticipated to provide with high electrochemical stability and good mechanical properties, and the PEG side chains enable the block copolymers with a promising ionic conductivity. The structure of the obtained polymer was characterized by ${ }^{1} \mathrm{H}$ NMR and FTIR. The thermal and electrochemical properties of these electrolytes were systematically investigated. The results showed that PDLLA-SPEs exhibit good thermal stability and possess a wide electrochemical window and a relatively high ionic conductivity. Furthermore, the allsolid-state $\mathrm{LiFePO}_{4} / \mathrm{Li}$ cell displayed extraordinary cycling and rate performances at $60{ }^{\circ} \mathrm{C}$ by integrating cathode with PDLLASPE. The as-developed PDLLA-SPE is attractive for using as solid electrolyte in lithium ion batteries with enhanced ionic conductivity and long-term durability.

\section{Experimental}

\section{Materials}

d,L-Lactide (DLLA, 99.0\%, J\&K), methacryloyl chloride (97.0\%, Aldrich), triethylamine (>99.5\%, Aladdin), methanol $(\geq 99.5 \%$, Aladdin), inositol (99.0\%, Macklin), 4-dimethylaminopyridine

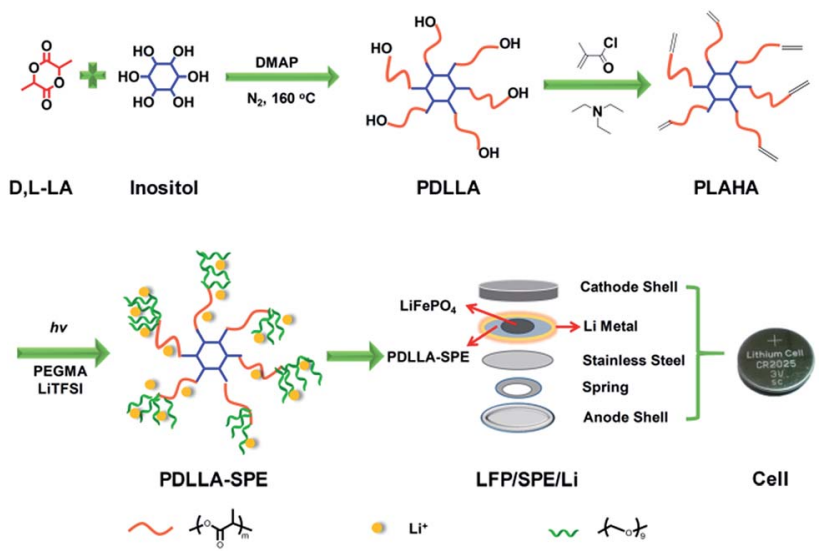

Fig. 1 Schematic illustration for the preparation process of PLAHA, PDLLA-SPEs and the cell.

(DMAP, 99.0\%, Macklin), Irgacure 1173 (photoinitiator, BASF), PEGMA $\left(M_{\mathrm{n}}=500 \mathrm{~g} \mathrm{~mol}^{-1}\right.$, Sigma-Aldrich $)$ and PEO $\left(M_{\mathrm{n}}=\right.$ $600000 \mathrm{~g} \mathrm{~mol}^{-1}$, Sigma-Aldrich) were used as received without further purification, unless stated otherwise. Dichloromethane $\left(\mathrm{CH}_{2} \mathrm{Cl}_{2}, \geq 99.5 \%\right.$, Aladdin) and acetonitrile (ACN, $\geq 99.5 \%$, Aladdin) were dried with $\mathrm{CaH}_{2}$ and distilled under reduced pressure prior to use. Lithium bis(trifluoromethanesulfonyl)imide (LiTFSI, 99\%, Shenzhen Capchem Technology Co., Ltd.) was dried under vacuum at $80{ }^{\circ} \mathrm{C}$ for $24 \mathrm{~h}$ before use. $\mathrm{LiFePO}_{4}$ (LFP), Super $\mathrm{P}$ and other battery accessories were purchased from Shenzhen Kejing.

\section{Synthesis of six-arm star PDLLA macromonomer}

PDLLA was synthesized by ring-opening polymerization (ROP) of $\mathrm{D}, \mathrm{L}$-lactide (DLLA) according to literature. ${ }^{23}$ Typically, the bulk polymerization of DLLA was conducted at $160{ }^{\circ} \mathrm{C}$, using inositol as the initiator and DMAP as the organo-catalyst under a nitrogen atmosphere. Subsequently, methacryloyl chloride was utilized to prepare the vinyl-functionalized PDLLA. The asprepared vinyl end-functionalized PDLLA macromonomer was hereafter labeled as PLAHA (as shown in Fig. 1).

\section{Preparation of PDLLA-SPE and PEO-SPE membranes}

The fabrication of PDLLA-SPE and PEO-SPE membranes were conducted as follows and all operations were carried out in a glove box under an argon atmosphere $\left(\mathrm{H}_{2} \mathrm{O}<1 \mathrm{ppm}\right)$.

PDLLA-SPE membranes were fabricated via a facile in situ solvent-free radical polymerization method (shown in Fig. 1). The as-prepared polymer PLAHA and lithium salt (LiTFSI) were added to PEGMA in sequence under intense stirring to form a homogeneous solution. The weight ratio of PLAHA to PEGMA was set to $1: 4$ in order to obtain a solution with proper viscosity. The concentration of LiTFSI was controlled by varying $\mathrm{EO} / \mathrm{Li}^{+}$molar ratios from 8 to 24 . Then the photoinitiator $(1 \mathrm{wt} \%$ to the monomer mixtures) was added to the solution, followed by pouring the homogeneous solution onto different substrates of stainless steels, Li metal anodes or cathode layers, depending on the different characterization requirements. The PDLLA-SPE 
membranes were obtained by in situ radical polymerization under UV irradiation for 20 minutes. Finally, the prepared PDLLA-SPE membranes were dried under vacuum at $60{ }^{\circ} \mathrm{C}$ for $48 \mathrm{~h}$ prior to use. The average thickness of the membranes is approximately $500 \mu \mathrm{m}$. To confirm the cross-linking density, PDLLA-PEG copolymer was immersed in dichloromethane for 3 days. Subsequently, the undissolved solid was dried under vacuum at $60{ }^{\circ} \mathrm{C}$ for $24 \mathrm{~h}$. The cross-linking density is about $95 \%$, as calculated by the weight ratio of the sample before and after immersion.

PEO-SPE membranes were prepared by conventional solution-casting technique. ${ }^{24}$ PEO and LiTFSI were dissolved in acetonitrile with $\mathrm{EO} / \mathrm{Li}^{+}=16$. A homogeneous solution was obtained after intense stirring, which was casted into a Teflon plate and the solvent was allowed to evaporate slowly for $24 \mathrm{~h}$ in a desiccator. Finally, the prepared PEO-SPE membranes were dried under vacuum at $60{ }^{\circ} \mathrm{C}$ for $48 \mathrm{~h}$ and then punched into circles with diameters of $17 \mathrm{~mm}$ for further measurements. The average thickness of the membranes was measured to be $\sim 500$ $\mu \mathrm{m}$.

\section{Assembly of all-solid-state cells}

The LFP cathode was prepared by automobile doctor blade from a mixture composted of $70 \mathrm{wt} \%$ LFP, $20 \mathrm{wt} \%$ SPE as a binder and $10 \mathrm{wt} \%$ Super-P in acetonitrile. The SPE used here was prepared by dissolving a lithium salt $\left(\mathrm{LiClO}_{4}\right)$ in the as-prepared block copolymer at an $\mathrm{EO} / \mathrm{Li}^{+}$ratio of $16: 1 . \mathrm{LiClO}_{4}$ was used instead of LiTFSI, is due to its much lower hydroscopicity. CR2025 coin cells with the LFP/SPE/Li were assembled for further test.

\section{Characterization and measurements}

Structure, morphology and thermal property. The structures of PDLLA and PDLLA-SPEs were characterized by nuclear magnetic resonances $\left({ }^{1} \mathrm{H}\right.$ NMR) and Fourier transformation infrared spectroscopy (FTIR). ${ }^{1} \mathrm{H}$ NMR were recorded on a Bruker Ascend ${ }^{\mathrm{TM}} 400 \mathrm{MHz}$ nuclear magnetic resonance spectrometer at room temperature using deuterochloroform $\left(\mathrm{CDCl}_{3}\right)$ as solvent and tetramethylsilane (TMS) as the internal standard. FTIR analysis was performed on a Bruker Vector 333 FTIR spectrometer using infrared spectrum analyzer over the range of $4000-500 \mathrm{~cm}^{-1}$ at room temperature. The surface morphology was studied using a TESCAN MIRA3 field emission scanning electron microscopy.

The thermal property of the as-prepared PDLLA-SPEs was characterized by differential scanning calorimetry (DSC) and thermogravimetric analysis (TGA). DSC was performed using a Mettler-Toledo differential scanning calorimetry at temperatures ranging from -60 to $100{ }^{\circ} \mathrm{C}$ with a heating/cooling rate of $10{ }^{\circ} \mathrm{C} \min ^{-1}$ under a nitrogen atmosphere. TGA was carried out on a Mettler-Toledo thermogravimetric analyzer from 30 to $600{ }^{\circ} \mathrm{C}$ with a heating rate of $10{ }^{\circ} \mathrm{C} \mathrm{min}{ }^{-1}$ under a nitrogen atmosphere. The crystallization behavior was examined by a Bruker Eco D8 X-ray diffractometer (XRD). The degree of crystallinity (\%) was calculated from the ratio of the integrated intensity of the crystal peaks to the total integrated intensity.
Electrochemical properties. All electrochemical measurements were carried out on a Solartron 1260 multi-channel potentiostat electrochemical workstation. The ionic conductivities of SPEs were measured by electrochemical impedance spectroscopy (EIS) with AC amplitude of $10 \mathrm{mV}$ over a temperature range from 30 to $100{ }^{\circ} \mathrm{C}$ and a frequency range of $10^{6}$ to $0.01 \mathrm{~Hz}$. The SPE membranes were sandwiched between two stainless-steel plate electrodes (SS) to assemble symmetrical SS/ PDLLA-SPE/SS cells. The ionic conductivity $\left(\sigma, \mathrm{S} \mathrm{cm}^{-1}\right)$ was calculated using eqn (1):

$$
\sigma=\frac{L}{R_{\mathrm{b}} S}
$$

where $L(\mathrm{~cm}), R_{\mathrm{b}}(\Omega)$ and $S\left(\mathrm{~cm}^{2}\right)$ represent the thickness of the SPEs, the impedance of the bulk electrolyte and the contacting area between SPEs and stainless steel, respectively. The electrochemical stability window of the SPEs were studied by liner sweep voltammograms (LSV) over a voltage range of 0 to $7 \mathrm{~V}$ ( $v s$. $\mathrm{Li}^{+} / \mathrm{Li}$ ) at a scanning rate of $1 \mathrm{mV} \mathrm{s}^{-1}$, using coin cells of SS/SPE/ Li under ambient temperature.

Cell performance. All the cells were tested on a Land charge/ discharge instrument (Wuhan Rambo Testing Equipment Co., Ltd.). The rate and cycling performance at $0.1 \mathrm{C}$ of the all solidstate cells were performed within a voltage range of $2.8-3.8 \mathrm{~V}$ at $60{ }^{\circ} \mathrm{C}$. And the $\mathrm{C}$-rate in both of the two measurements were defined based on $1 \mathrm{C}=150 \mathrm{~mA} \mathrm{~h} \mathrm{~g}^{-1}$.

\section{Results and discussion}

\section{Structure of six-arm star PDLLA macromonomer}

The synthesis of PDLLA macromonomer (PLAHA) that endcapped with $-\mathrm{C}=\mathrm{C}$ - double bonds follows two steps: the preparation of hydroxyl-terminated PDLLA by ring-opening polymerization (ROP) of DLLA and acylation of the terminal hydroxyl functionalities.

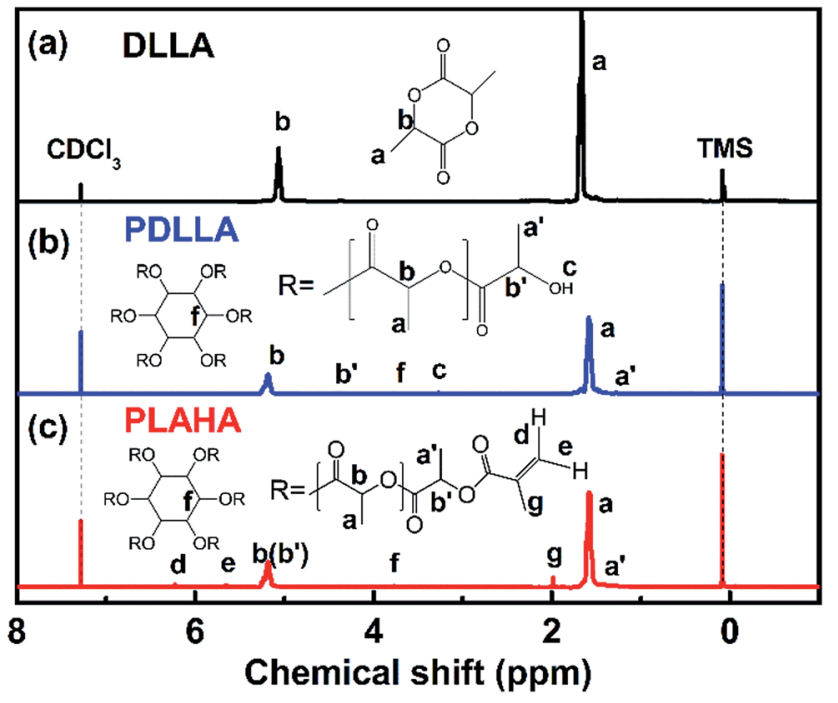

Fig. $2{ }^{1} \mathrm{H}$ NMR spectra of DLLA, PDLLA and PLAHA. 
To demonstrate the successful synthesis of PLAHA, the ${ }^{1} \mathrm{H}$ NMR spectras of DLLA, PDLLA and PLAHA are shown in Fig. 2. The resonance a (chemical shift $\delta=1.45-1.55 \mathrm{ppm})$ and $\mathrm{b}(\delta=$ 5.10-5.35 ppm) are assigned to the proton of $-\mathrm{CH}_{3}$ and $-\mathrm{CH}$ at the PDLLA backbone, respectively. The resonance $\mathrm{a}^{\prime}(\delta=1.30-$ $1.35 \mathrm{ppm})$ and $\mathrm{b}^{\prime}(\delta=4.35-4.39 \mathrm{ppm})$ are assigned to the proton of $-\mathrm{CH}_{3}$ and $-\mathrm{CH}$ at the chain end of the PDLLA backbone. ${ }^{23,25,26}$ The appearance of the peak c at 3.35-3.40 ppm (terminal - $\mathrm{OH}$ of PDLLA) and peak $\mathrm{f}$ at 3.75-4.80 ppm (the characteristic $-\mathrm{CH}$ - of the six-membered ring of inositol) in NMR spectrum of PDLLA confirms the inositol-initiated ring-opening polymerization of DLLA. Comparing the ${ }^{1} \mathrm{H}$ NMR spectrum of PLAHA with that of PDLLA, the characteristic resonance of $-\mathrm{OH}$ at $3.35-3.40 \mathrm{ppm}$ decreased dramatically, together with the arising of the new peaks $\mathrm{d}$ and e assigned to the protons on the $-\mathrm{C}=\mathrm{C}$ - double bond, clearly prove that $-\mathrm{C}=\mathrm{C}-$ was successfully induced into PDLLA by acylation reaction.

To further confirm the structure of the synthesized polymers, the FTIR spectra of PEGMA, DLLA, PDLLA, PLAHA and PDLLASPE are shown in Fig. 3. Characteristic absorption peaks at $3038-2793 \mathrm{~cm}^{-1}$ and $1459 \mathrm{~cm}^{-1}$ that attributed to the stretching vibration and bending vibration of $\mathrm{CH}_{3}$ and $\mathrm{CH}$, respectively, are observed in all of the spectra, as reported previously. ${ }^{27}$ The strong peaks at $1760 \mathrm{~cm}^{-1}$ are attributed to the stretching vibration of $\mathrm{C}=\mathrm{O}$. The symmetrical and antisymmetric stretching vibration peaks of C-O locate at 1102 and $1260 \mathrm{~cm}^{-1}$, respectively. Comparing the spectrum of DLLA with that of PDLLA, a new characteristic peak shows up at $3500 \mathrm{~cm}^{-1}$ of the stretching vibration of terminal hydroxyl $\mathrm{O}-\mathrm{H}$ in PDLLA. The ring skeleton vibration peaks of DLLA at 960 and $650 \mathrm{~cm}^{-1}$ (ref. 28) decrease dramatically. From the analysis of FTIR spectra, one can conclude that PDLLA was synthesized successfully via ring-opening polymerization of DLLA. After acylation, the corresponding characteristic peak of - $\mathrm{OH}$ from PDLLA decrease dramatically and the characteristic vibration of $-\mathrm{C}=\mathrm{C}-$ stretching emerges at $1638 \mathrm{~cm}^{-1}$ for PLAHA, indicating that the

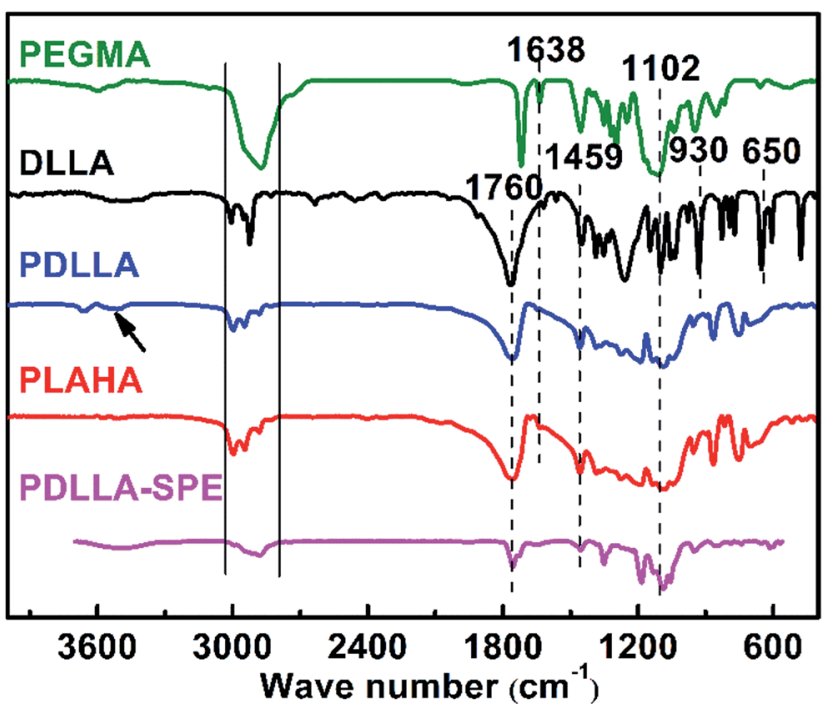

Fig. 3 FTIR spectra of PEGMA, DLLA, PDLLA, PLAHA and PDLLA-SPE.
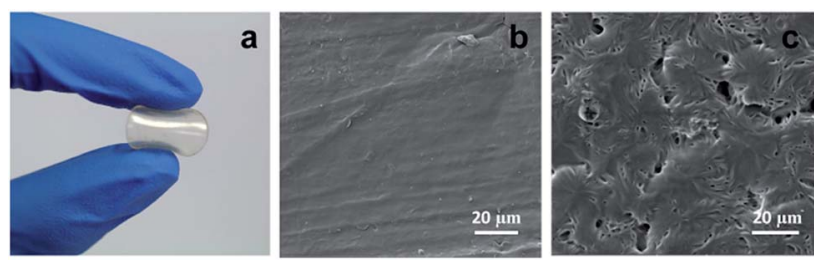

Fig. 4 (a) Photograph of PDLLA-SPE; (b) typical SEM image of PDLLASPE; (c) typical SEM image of PEO-SPE.

$-\mathrm{C}=\mathrm{C}-$ terminated PLAHA was successfully synthesized. The FTIR results are in consistent with the ${ }^{1} \mathrm{H}$ NMR results and all these results clearly confirm the successful synthesis of the PLAHA polymer.

\section{Morphology of PDLLA-SPE membranes}

The macro and micro morphologies of PDLLA-SPE membranes are shown in Fig. 4. The PDLLA-SPE membrane is a uniform, transparent, self-standing film with good flexibility, as shown in Fig. 4a. The thickness is approximately $500 \mu \mathrm{m}$, and can be adjusted by tuning the dosage of precursor solution. The tensile strength is about $109 \mathrm{kPa}$ as detected by tensile experiment as shown in Fig. S1.† The SEM analysis indicates that the surface of PDLLA-SPE membrane is smooth and homogenous, without any visible porous or crystal structure (Fig. 4b). As a sharp contrast, the SEM image clearly shows a typical semi-crystalline phase and porous morphology at the surface of PEO-SPE membrane, as shown in Fig. 4c. This is highly in agreement with literature. ${ }^{\mathbf{2 9}, 30}$ The much smother surface of PDLLA-SPE membrane may have a strong effect in battery performance.

\section{Ionic conductivity of SPES}

The ionic conductivity of the as-obtained PDLLA-SPEs were investigated systematically, to study the effects of lithium salt concentration $\left(\mathrm{EO} / \mathrm{Li}^{+}\right)$and temperature. It was reported that the concentration of lithium salt in a polymer electrolyte plays a critical role in its ionic conductivity. ${ }^{31}$ In order to find a preferred $\mathrm{EO} / \mathrm{Li}^{+}$ratios for high ionic conductivity, the conductivity plot for PDLLA-SPE as a function of the $\mathrm{EO} / \mathrm{Li}^{+}$ ratios is presented in Fig. 5a. The ionic conductivity of SPE showed an increase with the $\mathrm{EO} / \mathrm{Li}^{+}$ratio was raised from 8 to 16
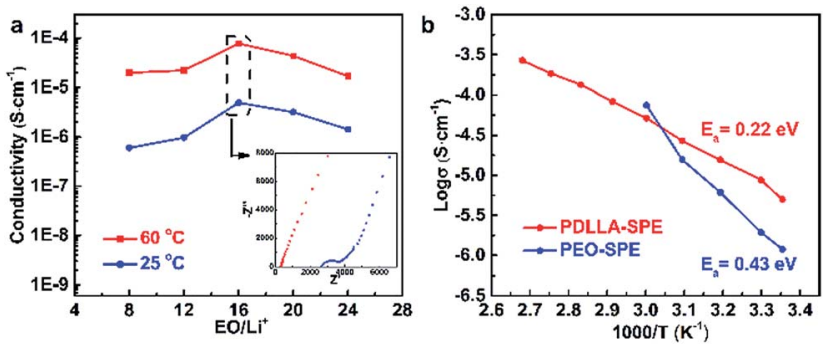

Fig. 5 (a) The ionic conductivity of PDLLA-SPEs as a function of molar ratio of $\mathrm{EO} / \mathrm{Li}^{+}$at $25^{\circ} \mathrm{C}$ and $60{ }^{\circ} \mathrm{C}$. Inset shows the $\mathrm{AC}$ impedance spectra of symmetrical battery when $\mathrm{EO} / \mathrm{Li}^{+}$is $16: 1$; (b) Arrhenius plots for SPEs with the molar ratio of $\mathrm{EO} / \mathrm{Li}^{+}=16: 1$. 
and followed by a decrease while the $\mathrm{EO} / \mathrm{Li}^{+}$value was increased further to 24 . This is mainly because that the free $\mathrm{Li}^{+}$carrier increases with the rising of lithium salt concentration at the low concentration range, resulting in a gradual improvement in conductivity. However, with the further increase of lithium salt concentration, the formation of ion pairs lowers the $\mathrm{Li}^{+}$carrier concentration. ${ }^{29}$ The highest conductivity of SPE was achieved at a $\mathrm{EO} / \mathrm{Li}^{+}$ratio of 16 and the optimal values are $9.7 \times 10^{-5}$ and $8.0 \times 10^{-6} \mathrm{~S} \mathrm{~cm}^{-1}$ at 60 and $25{ }^{\circ} \mathrm{C}$, respectively.

To further understand the conductivity trend as a function of temperature, the solid electrolyte with an $\mathrm{EO} / \mathrm{Li}^{+}$ratio of 16 was studied. In general, the conductivity of the SPE increases with rising temperature from 30 to $100{ }^{\circ} \mathrm{C}$. It is well known that the mobility of polymer chain is enhanced at higher temperatures, which favors the complexation and dissociation of $\mathrm{Li}^{+}$with polymer segments and accelerates the transfer rate of $\mathrm{Li}^{+}$. In addition, the lithium salt, LiTFSI, has a higher degree of dissociation, resulting in a further improvement of ionic conductivity. ${ }^{32}$ As a control, the temperature-dependent ionic conductivity of PEO-SPE with the same lithium salt concentration was also tested, as presented in Fig. 5b. It is obvious that the PDLLA-SPE has a higher conductivity than that of PEO-SPE in the temperature range of 25 to $50{ }^{\circ} \mathrm{C}$. This is most likely due to the non-crystalline structure of PDLLA-SPE, as illustrated by the results of DSC and XRD. The higher conductivity of PEO-SPE over that of PDLLA-SPE at $60{ }^{\circ} \mathrm{C}$ is attributed to the melting of PEO crystals at elevated temperature, resulting in an amorphous morphology and an enhanced ionic conductivity. The classical Arrhenius theory ${ }^{\mathbf{3 0 , 3 3 , 3 4}}$ was used to fit the polymer electrolyte conductivity by eqn (2):

$$
\sigma=\sigma_{0} \exp \left(-E_{\mathrm{a}} / k T\right)
$$

where the $\sigma_{0}$ is the pre-exponential factor; $E_{\mathrm{a}}$ is the activation energy for $\mathrm{Li}^{+}$conduction and the $k$ represents the Boltzmann constant. The Arrhenius plots is shown in Fig. 5b. The activation energy is the essential condition for ions to migrate in SPEs, as described previously. ${ }^{34,35}$ The calculated $E_{\text {a }}$ of PDLLASPE is $0.22 \mathrm{eV}$, much lower than that of PEO-SPE. This result implies that $\mathrm{Li}^{+}$transport through the PDLLA-SPE membrane is easier than in PEO-SPE at the same conditions.

\section{Thermal property and crystallization behavior of PDLLA-SPEs}

Thermal property of the PDLLA-SPE plays an important role in the practical application of SPE in lithium ion batteries, which was characterized by DSC and TGA. Fig. 6a shows the DSC curves of SPEs as a function of lithium salt concentrations. The PDLLA-SPEs show no melting peak in the scanning temperature range, which implies the PDLLA-SPEs are amorphous. The glass transition temperatures $\left(T_{\mathrm{g}}\right)$ at $40-50{ }^{\circ} \mathrm{C}$ are obviously attributed to PDLLA, as reported in literature. ${ }^{18}$ Notably, the $T_{\mathrm{g}} \mathrm{S}$ of the PEG segments were elevated by the increase of the lithium salt concentration, to the values of $-48,-46,-42,-36$ and $-34{ }^{\circ} \mathrm{C}$, respectively. This is attributed to the formation of complex between $\mathrm{Li}^{+}$and polymer chains when the van der Waals interactions increase with lithium salt concentration. ${ }^{\mathbf{1 4 , 2 9 , 3 6 , 3 7}}$ According to the free-volume transport mechanism, ${ }^{38}$ the
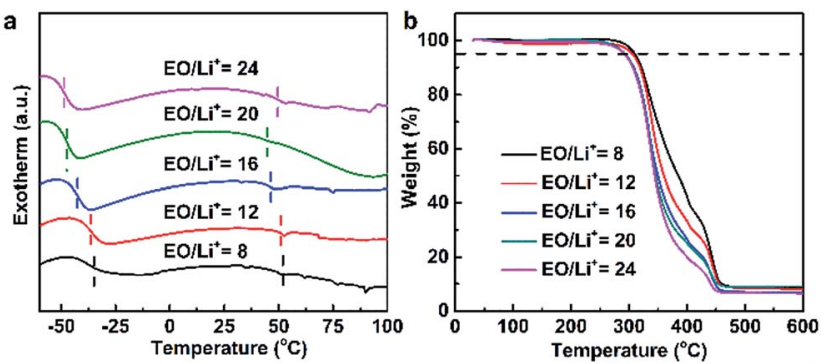

Fig. 6 The thermal property of the prepared PDLLA-SPEs with different lithium salt concentrations: (a) DSC curves, (b) TGA thermograms.

mobile of the polymer segments favors the transport of free ion. ${ }^{39}$ In other words, polymers with higher $T_{\mathrm{g}}$ would restrict the migration of carriers. Thus, a lower $T_{\mathrm{g}}$ (or a lower lithium concentration) is more favorable for $\mathrm{Li}^{+}$transport in SPEs. It is noteworthy that when $\mathrm{EO} / \mathrm{Li}^{+}$is greater than 16 , although the $T_{\mathrm{g}}$ is lower, a satisfied conductivity cannot be achieved due to the low the carrier concentration resulting from the barren lithium salt concentration. As a consequence, there must be an optimal $\mathrm{EO} / \mathrm{Li}^{+}$ratio for PDLLA-SPE, at which the influence from $T_{\mathrm{g}}$ and carrier concentration can be balanced. In our case, the optimum value of EO/ $\mathrm{Li}^{+}$of PDLLA-SPE is 16 , which was proved by EIS (as shown in Fig. 5a).

The thermal stability of the PDLLA-SPEs was investigated by TGA, as shown in Fig. 6b. The TGA curves of SPE membranes with different lithium salt concentrations show basically the same trend. All samples show a common first stage of weight loss at about $270{ }^{\circ} \mathrm{C}$, due to the decomposition of polymer matrix, slightly higher than the reported value of $240{ }^{\circ} \mathrm{C}$ of PDLLA- $b$-PEG copolymers. ${ }^{18}$ The second stage of weight loss at approximately $360-450{ }^{\circ} \mathrm{C}$ is attributed to the decomposition of LiTFSI. ${ }^{40}$ In summary, the SPE in this work is thermal stable, and are capable to fully meet the demands of practical application of solid state lithium ion battery.

$\mathrm{X}$-ray patterns depicted in Fig. S2 $\uparrow$ were employed to identify the phases of PDLLA-SPE and PEO-SPE with the molar ratio of $\mathrm{EO} / \mathrm{Li}^{+}=16: 1$. The XRD pattern of PEO-SPE shows strong crystalline peaks at $19.1^{\circ}$ and $23.4^{\circ}$, as reported elsewhere. ${ }^{\mathbf{4 1 - 4 4}}$ The degree of crystallinity of PEO-SPE was calculated to be approximately $25 \%$. The high degree of crystallinity leads to a poor ionic conductivity of PEO-SPE at room temperature. ${ }^{4}$ In sharp contrast to PEO-SPE, only a broad peak located at around $20^{\circ}$ is observed in the XRD curves of PDLLA-SPE, implying that the PDLLA-SPE is totally amorphous and meanwhile the added LiTFSI is completely dissolved in the polymer matrix. ${ }^{45}$ The obtained result corroborate very well with the DSC results. The highly amorphous nature of PDLLA-SPE contributes significantly in ionic conductivity.

\section{Electrochemical stability of SPEs}

The electrochemical stability of the polymer electrolyte probed by linear voltammetry scan is depicted in Fig. S3. $\dagger$ As a comparison, the PEO-SPE prepared by traditional solution 


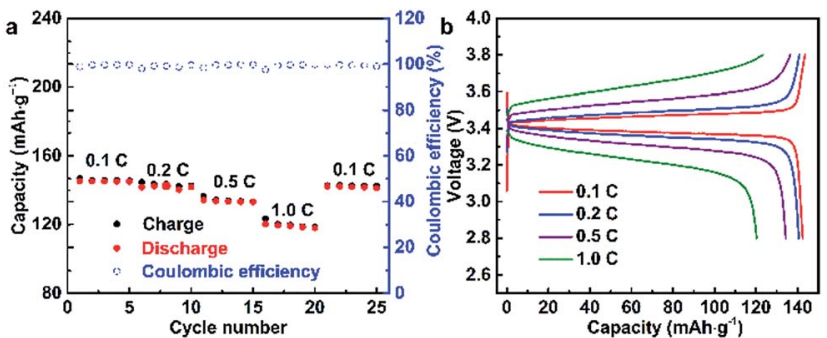

Fig. 7 The rate performance of LFP/PDLLA-SPE/Li battery with the molar ratio of $\mathrm{EO} / \mathrm{Li}^{+}=16: 1$ at $60{ }^{\circ} \mathrm{C}$ : (a) the rate capability and (b) the charge/discharge profiles of LFP/PDLLA-SPE/Li at different current densities $(0.1 \mathrm{C}, 0.2 \mathrm{C}, 0.5 \mathrm{C}$ and $1.0 \mathrm{C})$

casting method $\left(\mathrm{EO} / \mathrm{Li}^{+}=16\right)$ was used as a control at the same condition. As shown in Fig. 8, the current density shows a steep increase at $4.7 \mathrm{~V}$ versus $\mathrm{Li} / \mathrm{Li}^{+}$at $60{ }^{\circ} \mathrm{C}$ for PEO-SPE, which represents the oxidative decomposition of electrolyte. ${ }^{46}$ However, the LSV curve of PDLLA-SPE is significantly smoother and no oxidation is observed below $5.1 \mathrm{~V}$. Clearly, PDLLA-SPE has a wider electrochemical window and higher electrochemical stability. This is mostly likely due to the existence of ester groups in PDLLA which shows good electrochemical stability, as reported previously. ${ }^{16,47}$

\section{Cell performance}

To verify the feasibility of the as-prepared SPEs, the LFP/SPE/Li batteries were assembled to test the durable rate capability and long-term cycling stability. The mass loading of the active materials was $0.96 \mathrm{mg} \mathrm{cm}^{-2}$ in the LFP/SPE/Li batteries. The rate performance of $\mathrm{LFP} / \mathrm{SPE} / \mathrm{Li}$ at $60^{\circ} \mathrm{C}$ with the current density of $0.1 \mathrm{C}$ to $1.0 \mathrm{C}$ is shown in Fig. 7a. It can be found that the discharge capacities are $145.3,142.5,134.3,120.3$ and $142.3 \mathrm{~mA} \mathrm{~h} \mathrm{~g}^{-1}$, at various current rates of $0.1 \mathrm{C}, 0.2 \mathrm{C}, 0.5 \mathrm{C}, 1 \mathrm{C}$ and $0.1 \mathrm{C}$, respectively. The discharge capacities are much higher than those of PEO-SPE reported. ${ }^{48}$

Fig. $7 \mathrm{~b}$ presents the charge/discharge performance of PDLLA-based $\mathrm{Li} / \mathrm{LiFePO}_{4}$ cell at $60{ }^{\circ} \mathrm{C}$ with different current densities. The initial specific discharge capacities at different current density show the same trend compared with the rate capacity shown in Fig. 7a. With the increase of current density, the capacity decreases and is maintained at $120.3 \mathrm{~mA} \mathrm{~h} \mathrm{~g}{ }^{-1}$ at 1C $(82.8 \%$ of the capacity at $0.1 \mathrm{C})$. Moreover, the cell exhibits a low polarization voltage at $0.1 \mathrm{C}$ with flat voltage plateaus around $3.4 \mathrm{~V}$, which means a good electrochemical reversibility for the cell using PDLLA-SPE. ${ }^{\mathbf{4 9}, 50}$ Even though the polarization voltage gradually enlarges with the rate increasing, the discharge capacity almost recovers completely when the rate is finally returned to the initial $0.1 \mathrm{C}$, which conforms the PDLLASPE is structurally and electrochemically stable.

Fig. 8 shows the cycling performance of all-solid-state LFP/ $\mathrm{SPE} / \mathrm{Li}$ batteries at the current density of $0.2 \mathrm{C}$ at $60{ }^{\circ} \mathrm{C}$. The initial discharge capacity of LFP/PDLLA-SPE/Li is $144.7 \mathrm{~mA} \mathrm{~h} \mathrm{~g}^{-1}$ and remains $125.8 \mathrm{~mA} \mathrm{~h} \mathrm{~g}^{-1}$ after 250 cycles. The capacity retention rate is about $86.9 \%$. The initial discharge capacity of the conventional LFP/PEO-SPE/Li shows

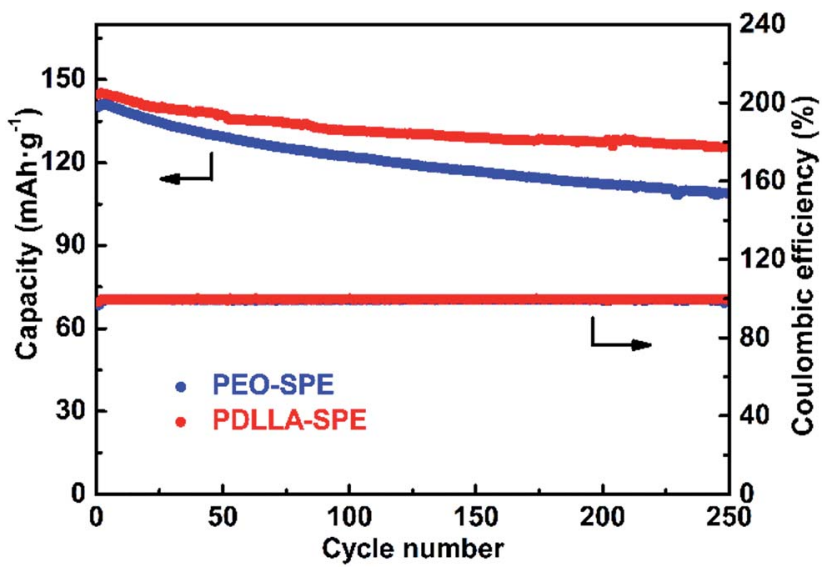

Fig. 8 The cycling performance of PDLLA-SPE and PEO-SPE with the molar ratio of $\mathrm{EO} / \mathrm{Li}^{+}=16: 1$ at $60{ }^{\circ} \mathrm{C}$ at the current density of $0.2 \mathrm{C}$.

a similar value of $140.4 \mathrm{~mA} \mathrm{~h} \mathrm{~g}^{-1}$, but with a significantly lower capacity retention rate of $77.5 \%\left(108.9 \mathrm{~mA} \mathrm{~h} \mathrm{~g}^{-1}\right)$ under the same conditions. It's obvious that the cycling performance of the integrated LFP/PDLLA-SPE/Li is much better than that of the conventional one. This superiority is probably ascribed to the better interfacial compatibility between PDLLA-SPE and two electrodes. ${ }^{51}$ Besides, the PDLLA-SPE is entirely amorphous as discussed above, which may also contribute to the improved cycling performance. In addition, the coulombic efficiency is almost $100 \%$ during the long-term cycling process, further verifying the extraordinary cycling reversibility of PDLLA-SPEs.

\section{Conclusions}

In this study, a series of novel SPEs based on a star-comb PDLLA-PEG copolymer and LiTFSI were prepared through solvent-free radical polymerization irradiated by UV. The chemical structure of the obtained polymers was characterized by ${ }^{1} \mathrm{H}$ NMR and FTIR. The surface of the free-standing PDLLA-SPE membranes is smooth and homogenous, as observed by SEM. The phase of the PDLLA-SPEs is totally amorphous, as conformed by XRD. The thermal and electrochemical properties and cell performance of these electrolytes were investigated. The PDLLA-SPEs exhibit good thermal stability with $T_{\mathrm{d}}{ }^{5 \%} \mathrm{~S}$ of $\sim 270{ }^{\circ} \mathrm{C}$ and low $T_{\mathrm{g}} \mathrm{S}$ of -48 to $-34{ }^{\circ} \mathrm{C}$. The optimal ionic conductivities are $9.7 \times 10^{-5} \mathrm{~S} \mathrm{~cm}^{-1}$ and $8.0 \times 10^{-6} \mathrm{~S} \mathrm{~cm}^{-1}$ at $60^{\circ} \mathrm{C}$ and $25^{\circ} \mathrm{C}$, respectively, at an $\mathrm{EO} / \mathrm{Li}^{+}$ ratio of $16: 1$. Besides, the PDLLA-SPEs has a wide electrochemical window up to $5.1 \mathrm{~V}$, which is much wider than that of PEO-SPE. Furthermore, the all-solid-state $\mathrm{LiFePO}_{4} / \mathrm{Li}$ cell displays extraordinary cycling and rate performance at $60{ }^{\circ} \mathrm{C}$ due to the good interfacial compatibility between PDLLA-SPE and electrodes. In conclusion, the promising cycling and rate performance, together with a relatively high ionic conductivity of the six-arm star-comb PDLLA-SPE make it a attractive candidate of solid polymer electrolyte for all-solid-state lithium batteries. 


\section{Conflicts of interest}

There are no conflicts to declare.

\section{Acknowledgements}

The authors gratefully acknowledge the financial support from the Natural Science Foundation of Guangdong Province, China (grant no. 2016A030311031), the Fundamental Research Foundation of Shenzhen (grant no. 20170410160631170) and the Postdoctoral Science Foundation (grant no. 2016M590782). The authors are also grateful for the support from the members of the Advanced Polymeric Energy Materials Laboratory, Department of Materials Science and Engineering, South University of Science and Technology of China.

\section{Notes and references}

1 J. M. Tarascon and M. Armand, Nature, 2001, 414, 359-367.

2 P. G. Bruce, B. Scrosati and J. M. Tarascon, Angew. Chem., Int. Ed. Engl., 2008, 47, 2930-2946.

3 M. Marcinek, J. Syzdek, M. Marczewski, M. Piszcz, L. Niedzicki, M. Kalita, A. Plewa-Marczewska, A. Bitner, P. Wieczorek, T. Trzeciak, M. Kasprzyk, P. Łężak, Z. Zukowska, A. Zalewska and W. Wieczorek, Solid State Ionics, 2015, 276, 107-126.

4 G. B. Appetecchi, F. Croce, L. Persi, F. Ronci and B. Scrosati, Electrochim. Acta, 2000, 45, 1481-1490.

5 J. Xi, X. Qiu, M. Cui, X. Tang, W. Zhu and L. Chen, J. Power Sources, 2006, 156, 581-588.

6 X.-L. Wu, Y.-H. Li, N. Wu, S. Xin, J.-H. Kim, Y. Yan, J.-S. Lee and Y.-G. Guo, Solid State Ionics, 2013, 245-246, 1-7.

7 L. J. Goujon, A. Khaldi, A. Maziz, C. Plesse, G. T. M. Nguyen, P.-H. Aubert, F. Vidal, C. Chevrot and D. Teyssié, Macromolecules, 2011, 44, 9683-9691.

8 M.-H. Ryou, Y. M. Lee, K. Y. Cho, G.-B. Han, J.-N. Lee, D. J. Lee, J. W. Choi and J.-K. Park, Electrochim. Acta, 2012, 60, 23-30.

9 L. Ding, Polymer, 1997, 38, 4267-4273.

10 J.-C. Daigle, A. Vijh, P. Hovington, C. Gagnon, J. HamelPâquet, S. Verreault, N. Turcotte, D. Clément, A. Guerfi and K. Zaghib, J. Power Sources, 2015, 279, 372-383.

11 T. Niitani, M. Amaike, H. Nakano, K. Dokko and K. Kanamura, J. Electrochem. Soc., 2009, 156, A577-A583.

12 S. Ren, H. Chang, L. He, X. Dang, Y. Fang, L. Zhang, H. Li, Y. Hu and Y. Lin, J. Appl. Polym. Sci., 2013, 129, 1131-1142.

13 M. Guo, M. Zhang, D. He, J. Hu, X. Wang, C. Gong, X. Xie and Z. Xue, Electrochim. Acta, 2017, 255, 396-404.

14 T. Zheng, Q. Xing, S. Ren, L. Zhang and H. Li, Ionics, 2015, 21, 917-925.

15 H.-Y. Wu, D. Saikia, C.-P. Lin, F.-S. Wu, G. T. K. Fey and H.-M. Kao, Polymer, 2010, 51, 4351-4361.

16 B. Sun, J. Mindemark, K. Edström and D. Brandell, Solid State Ionics, 2014, 262, 738-742.

17 J. Chai, Z. Liu, J. Ma, J. Wang, X. Liu, H. Liu, J. Zhang, G. Cui and L. Chen, Adv. Sci., 2017, 4, 1600377.
18 Y. Lemmouchi, M. Murariu, A. M. D. Santos, A. J. Amass, E. Schacht and P. Dubois, Eur. Polym. J., 2009, 45, 2839-2848.

19 R. Auras, B. Harte, S. Selke and R. Hernandez, J. Plast. Film Sheeting, 2003, 19, 123-135.

20 K. W. Chew, T. C. Ng and Z. H. How, Int. J. Electrochem. Sci., 2013, 8, 6354-6364.

21 C. H. Tan, A. Ahmad and F. H. Anuar, Asian J. Chem., 2014, 26, S230-S236.

22 D. Garlotta, J. Polym. Environ., 2001, 9, 63-84.

23 F. Nederberg, E. F. Connor, M. Möller, T. Glauser and J. L. Hedrick, Angew. Chem., Int. Ed., 2001, 40, 2712-2715.

24 Y. Zhao, C. Wu, G. Peng, X. Chen, X. Yao, Y. Bai, F. Wu, S. Chen and X. Xu, J. Power Sources, 2016, 301, 47-53.

25 Z.-Y. Wang, H.-J. Zhao, Q.-F. Wang, R.-R. Ye and D. E. Finlow, J. Appl. Polym. Sci., 2010, 117, 1405-1415.

26 F. Carrasco, P. Pagès, J. Gámez-Pérez, O. O. Santana and M. L. Maspoch, Polym. Degrad. Stab., 2010, 95, 116-125.

27 S. L. Feng Li, A. El Ghzaoui, H. Nouailhas and R. Zhuo, Langmuir, 2007, 23, 2778-2783.

28 Z.-Y. Wang, Y.-M. Zhao and F. Wang, J. Appl. Polym. Sci., 2006, 102, 577-587.

29 M. Marzantowicz, J. R. Dygas, F. Krok, J. L. Nowiński, A. Tomaszewska, Z. Florjańczyk and E. ZygadłoMonikowska, J. Power Sources, 2006, 159, 420-430.

30 H. Gupta, S. Shalu, L. Balo, V. K. Singh, S. K. Chaurasia and R. K. Singh, RSC Adv., 2016, 6, 87878-87887.

31 A. Panday, S. Mullin, E. Gomez, N. Wanakule, V. L. Chen, A. Hexemer, J. Pople and N. P. Balsara, Macromolecules, 2009, 42, 4632-4637.

32 M. Park, X. Zhang, M. Chung, G. B. Less and A. M. Sastry, J. Power Sources, 2010, 195, 7904-7929.

33 D. Kumar and S. A. Hashmi, J. Power Sources, 2010, 195, 5101-5108.

34 B. Jinisha, K. M. Anilkumar, M. Manoj, V. S. Pradeep and S. Jayalekshmi, Electrochim. Acta, 2017, 235, 210-222.

35 F. Latif, M. Aziz, N. Katun, A. M. M. Ali and M. Z. Yahya, J. Power Sources, 2006, 159, 1401-1404.

36 A. Wang, H. Xu, Q. Zhou, X. Liu, Z. Li, R. Gao, N. Wu, Y. Guo, H. Li and L. Zhang, Electrochim. Acta, 2016, 212, 372-379.

37 H. Zhang, C. Liu, L. Zheng, W. Feng, Z. Zhou and J. Nie, Electrochim. Acta, 2015, 159, 93-101.

38 M. H. Cohen and D. Turnbull, J. Chem. Phys., 1959, 31, 11641169.

39 J. Mindemark, B. Sun, E. Törmä and D. Brandell, J. Power Sources, 2015, 298, 166-170.

40 Z. Lu, L. Yang and Y. Guo, J. Power Sources, 2006, 156, 555559.

41 M. Jaipal Reddy, J. Siva Kumar, U. V. Subba Rao and P. P. Chu, Solid State Ionics, 2006, 177, 253-256.

42 S. Song, M. Kotobuki, F. Zheng, Q. Li, C. Xu, Y. Wang, W. D. Z. Li, N. Hu and L. Lu, Solid State Ionics, 2017, 300, 165-168.

43 S. Das and A. Ghosh, J. Appl. Phys., 2015, 117, 174103.

44 V. K. Singh, S. Shalu, S. K. Chaurasia and R. K. Singh, RSC Adv., 2016, 6, 40199-40210. 
45 A. R. Polu, H.-W. Rhee, M. Jeevan Kumar Reddy, A. M. Shanmugharaj, S. H. Ryu and D. K. Kim, J. Ind. Eng. Chem., 2017, 45, 68-77.

46 T.-M. Liu, D. Saikia, S.-Y. Ho, M.-C. Chen and H.-M. Kao, $R S C$ Adv., 2017, 7, 20373-20383.

47 K. Kimura, M. Yajima and Y. Tominaga, Electrochem. Commun., 2016, 66, 46-48.
48 L. Damen, J. Hassoun, M. Mastragostino and B. Scrosati, J. Power Sources, 2010, 195, 6902-6904.

49 Q. Lu, J. Yang, W. Lu, J. Wang and Y. Nuli, Electrochim. Acta, 2015, 152, 489-495.

50 B. Chen, Q. Xu, Z. Huang, Z. Yanran, S. Chen and X. Xu, J. Power Sources, 2016, 331, 322-331.

51 B. Huang, Y. Zhang, M. Que, Y. Xiao, Y. Jiang, K. Yuan and Y. Chen, RSC Adv., 2017, 7, 54391-54398. 